\title{
Catalytic transesterification of glycerol: Optimization for production of glycerol carbonate
}

\author{
Po Kim Lo*, Hor Yan Phin \\ Barat, 31900 Kampar, Perak, Malaysia. \\ * Corresponding author: lopk@utar.edu.my
}

Department of Petrochemical Engineering, Faculty of Engineering and Green Technology, Universiti Tunku Abdul Rahman, Jalan Universiti, Bandar

\section{Article history}

Received 27 February 2018

Revised 28 March 2018

Accepted 21 May 2018

Published Online 14 April 2019

\begin{abstract}
The purpose of this research was to study the effect of reaction temperature, reaction time and dimethyl carbonate:glycerol (DMC:Gly) molar ratio on the conversion of glycerol and yield of glycerol carbonate. The reaction was further optimized with central composite design (CCD), 15 runs of transesterification reaction were conducted. Meanwhile, the calcined calcium oxide catalyst was fixed at catalyst/glycerol molar ratio at 0.06 while the stirring rate was maintained at $1000 \mathrm{rpm}$ for every runs. ANOVA results indicated that reaction temperature and reactants ratio (DMC:Gly) influenced the yield significantly. Synergy effect of reaction temperature with reaction time and reaction temperature with DMC:Gly molar ratio seem to have greater significance on the conversion instead of a single parameter. Under optimization studies, the maximum possible conversion and yield were $100 \%$ and $96.36 \%$ respectively which could be accomplished at $60.16^{\circ} \mathrm{C}$ reaction temperature with 1.19 hour reaction time and 3.04 DMC:Gly molar ratio. Compared to the highest conversion $(96.22 \%)$ and yield (95.83\%) achieved before the optimization with reaction carried out at $60{ }^{\circ} \mathrm{C}$, after 1.5 hours and at 3:1 DMC:Gly molar ratio, the optimization had resulted in the higher conversion with moderate reaction temperature and shorter reaction time.
\end{abstract}

Keywords: Transesterification, glycerol carbonate, calcium oxide

\section{INTRODUCTION}

Glycerol carbonate (GC) also known as glycerine carbonate or 4hydroxymethyl-2-oxo-1,3-dioxolane (Sonnati et al., 2013) is a promising green value added product with numerous applications in various industries. Glycerol carbonate considered as a sustainable substitution for petro-derivative compounds for ethylene carbonate or propylene carbonate (Ochoa-Gómez et al., 2009) due to it consists of hydroxyl functionality. Besides that, the presence of 4 reactive electrophilic centers in glycerol carbonate makes it becomes a key monomer in synthesis of various types of beneficial polymers such as polycarbonate, polyurethanes and polyether (Mathers \& Meier, 2011). On the other hand, glycerol carbonate also serves as a source for producing glycidol, polymeric liquid which used as an intermediate for glycidyl ether, a stabilizer for producing vinyl polymers, additives in oil and synthesis of epoxy resin diluent (Teng et al., 2014). Owing to its properties such as low toxicity, low volatility, low flammability and moisturizing ability, it is an ideal wetting agent and carrier for active species in medication, personal care and cosmetic field (Letcher \& Scott, 2012). It also acts as an electrolyte, a solvent in lithium ion batteries and novel components for carbon dioxide separation (Ochoa-Gómez et al., 2009). Recent discovery was on pretreatment of lignocellulosic biomass succeeded in ensuring the effectiveness of saccharification to generate fermentable sugars (Zhang et al., 2013). Apart from that, it has the potential to act as an anti-explosive additive for gasoline and diesel in the future (Indran et al., 2014).
Synthesis of glycerol carbonate can be either direct synthetic routes or indirect synthetic routes at which both are also glycerolbased reactions. Transesterification process is the most preferable and industrial feasible synthesis route among other reaction routes such as phosgenation and glycerolysis. This is because dimethyl carbonate is a low toxicity chemical and thus, having low environmental impact. Moreover, this process can be operated in milder condition without the formation of undesirable by-product such as isocyanic acid and biuret unlike glycerolysis process. Additionally, high conversion and product yield are achievable by using basic catalyst (Ochoa-Gómez et al., 2009). Nevertheless, this reaction requires higher ratio of DMC to shift the reaction equilibrium for attaining high yield of glycerol carbonate (Indran et al., 2014).

Therefore, the of effect of reaction temperature, reaction time and molar ratio of reactants (DMC:Gly) on the production of glycerol carbonate via $\mathrm{CaO}$ catalyzed transesterification were investigated in this study. Furthermore, parameters such as reaction temperature, reaction time and the molar ratio of reactants (DMC:Gly) were further optimized by using response surface methodology (RSM).

\section{LITERATURE REVIEW}

\section{Transesterification process}

Transesterification process is generally known as the carbonate exchange reaction between the alcohols and carbonate sources (Sonnati et al., 2013). For generation of glycerol carbonate through transesterification reaction, it can be classified into 2 categories such as chemical based transesterification and enzymatic transesterification. Meanwhile, chemical catalyzed transesterification 
can be further categorized into 2 different types such as homogeneous or heterogeneous of acid catalyzed transesterification reaction and homogeneous or heterogeneous base catalyzed transesterification reactions respectively (Teng et al., 2014). Regardless of the distinctive catalysts used for different transesterification processes, one mole of glycerol carbonate is surely produced from one mole of glycerol reacting with one mole of dimethyl carbonate (DMC) (Lanjekar \& Rathod, 2013). There are 2 options that need to be fulfilled in order to achieve high yield of glycerol carbonate. For instance, methanol serves as the reaction by-product is removed progressively or excessive dimethyl carbonate is used not only to serve as a substrate but acts also as a solvent to minimize the immiscibility between the glycerol and dimethyl carbonate. Nevertheless, the former option is not preferable due to the formation of azeotrope between the methanol and dimethyl carbonate with the weight ratio of 30:70 for dimethyl carbonate to methanol composition whereby the DMC might be removed together with methanol and thus affecting the yield of glycerol carbonate (Li \& Wang, 2011).

\section{Calcium oxide ( $\mathrm{CaO})$}

Calcium Oxide $(\mathrm{CaO})$ known as quicklime, unslaked lime, burnt lime or burnt limestone is originated from calcium carbonate $(\mathrm{CaCO} 3)$ which widely recognized as limestone (Kogel et al., 2006). Unlike calcium carbonate, calcium oxide does not exist naturally. It can be prepared by undergoing calcination of the limestone or with the sources that rich in limestone such as waste shells of mussel, cockle, and scallop (Buasri et al., 2013), duck eggshells (Tangboriboon et al., 2012), chicken eggshells (Mohadi et al., 2016) and fish bones (Lesbani et al., 2016). Calcium oxide $(\mathrm{CaO})$ possesses high melting point which is nearly $2600{ }^{\circ} \mathrm{C}$ and appears as amorphous white solid at room temperature. Owing to its high melting point, it is a stable compound that could withstand high pressure and temperature. During the manufacturing of calcium oxide, the reaction temperature is set in the range of from $900{ }^{\circ} \mathrm{C}$ to $1300{ }^{\circ} \mathrm{C}$ (Kogel et al., 2006) for the removal of carbon dioxide from limestone. Since the reaction is reversible, the carbon dioxide must be flushing out progressively to avoid the re-formation of calcium carbonate known as carbonation process (Stanmore \& Gilot, 2005). This is because calcium oxide is easily hydrated and carbonated by the moisture and carbon dioxide in the atmosphere which eventually leading to the deactivation of catalyst (Zabet et al., 2009).

Furthermore, the reaction is highly endothermic (Stanmore \& Gilot, 2005). The classification of the calcium oxide generated is dependent on the calcium carbonate content within the limestone (Kogel et al., 2006). Meanwhile, calcium oxide could react violently with water to form calcium hydroxide $(\mathrm{Ca}(\mathrm{OH}) 2)$ or hydrated lime that exists as white crust or dry powder (Farndon, 2000; Kogel et al., 2006). Synthesis of calcium hydroxide or slaked lime is highly exothermic and steam will be given off when water is poured directly to the calcium oxide.

\section{Calcination}

Calcination is referred as the process of heating on solid materials without air in order to remove the volatile compounds that chemically combined with the materials. It could also refer as the thermal degradation process of the solid materials for the sake of improving interaction between the constituents of the calcined materials (Herbert, 1985). Sometimes, it is used as the extraction method of metals from ores (Gupta, 2006). It is one of the most common unit operations in process metallurgy while the substrate is mostly carbonated sources. This unit operation mainly is to synthesize quicklime or calcium oxide from calcium carbonate sources for further industrial usage purposes (Gupta, 2006). It is an endothermic process which similar to the drying process whereby heat must be supplied for the process to take place. Nevertheless, drying and calcination are distinct in the aspect that drying process involves moisture removal only from the saturated material through evaporation (Kowalski, 2012) unlike calcination which involving the elimination of chemically bound substances from the solid materials. In drying, there will be volume shrinkage of the calcined materials by enhancing interaction between the particles and thus undeniably increasing the overall strength of the materials (Kowalski, 2012). Roasting which is one of the thermal processes that frequently confused with calcination is indeed distinguished from each other. Unlike calcination, roasting process applies heating to the solid materials at elevated temperature but below the melting point with the present of air to oxidize the impurities. It could be either exothermic or endothermic process. During calcination, the reactivity of calcium oxide is strongly dependent on the operating temperature and retention time (Verma, 1993). Theoretically, calcination of calcium carbonate with moderate operating temperature in the range from 750 ${ }^{\circ} \mathrm{C}$ to $850{ }^{\circ} \mathrm{C}$ is sufficient to generate calcium oxide with enhanced reactivity (Gupta, 2006). If operating temperature is beyond $1200{ }^{\circ} \mathrm{C}$, sintering of solid materials will occur that resulting in reduction of reactivity by increasing the density but decreasing the surface area of materials (Verma, 1993).

For glycerol carbonate synthesis, calcination serves as preparation step for the catalyst of the reaction that used to desorb the carbon dioxide and moisture chemically as calcium oxide is highly reactive towards these impurities upon contact (Zabeti et al., 2009). By doing this, the yield of the glycerol carbonate can be improved by avoiding the contamination of $\mathrm{Ca}$ active species which is the crucial element in producing glycerol carbonate. Calcined calcium oxide exhibits greater performance compared to uncalcined calcium oxide as the yield of glycerol carbonate could be promoted from $90.2 \%$ to $94 \%$ (Simanjuntak et al., 2011).

\section{METHODOLOGY/MATERIALS}

\section{Materials}

The calcium oxide $(\mathrm{CaO})$ catalyst powder, anhydrous glycerol with purity $99 \%$ and dimethyl carbonate (DMC) with purity more than 90\% were purchased from Sigma-Aldrich Co. The standard glycerol carbonate was purchased from Tokyo Chemical Industry Co,. Ltd. All the reagents and chemicals were analytical grades.

\section{Preparation of catalyst}

The calcium oxide $(\mathrm{CaO})$ was calcined in furnace at $900{ }^{\circ} \mathrm{C}$ for 3 hours and cooled overnight (Malyaadri, Jagadeeswaraiah, Sai Prasad, \& Lingaiah, 2011). The calcined $\mathrm{CaO}$ was then stored in a samples bottle with cap to prevent the $\mathrm{CaO}$ from contacting the moisture and carbon dioxide in the atmosphere. Subsequently, the bottle containing calcined catalyst was stored in the desiccator in which the desiccants could absorb moisture and thus preserving the moisture-sensitive chemicals.

\section{Transesterification reaction}

Glycerol Carbonate (GC) synthesis via glycerol (Gly) transesterification with dimethyl carbonate (DMC) with catalyst calcined calcium oxide $(\mathrm{CaO})$ was performed by using heating method. DMC and Gly were mixed with desired amount (Table 1) in a $250 \mathrm{~mL}$ three-neck round bottom flask and placed on the heating mantle fitted with magnetic stirrer and thermometer. The flask was connected with glass Graham condenser. The mixture was heated with stirring rate maintained at $1000 \mathrm{rpm}$ to the desired temperature and catalyst/glycerol molar ratio of 0.06 (Coldea et al., 2013) was then added to initiate the reaction. Different molar ratio DMC:Gly (1:1 to $5: 1)$ was charged into the flask at reaction temperature varied from 60 ${ }^{\circ} \mathrm{C}$ to $80{ }^{\circ} \mathrm{C}$ and 0.5 hour to 2.5 hours reaction time. After the reaction, the used catalyst was filtered by filter paper. Hence, the sample residues were then analyzed by fourier transform infrared (FTIR) spectroscopy.

\section{Fourier Transform Infrared (FTIR) spectroscopy}

FTIR results served as the fast quantification method to determine the glycerol conversion and yield of glycerol carbonate in pure glycerol transesterification. A standard calibration was done by running FTIR on the mixture of pure glycerol and standard glycerol carbonate in different ratio and recording the $1785 \mathrm{~cm}-1 / 923 \mathrm{~cm}-1$ area quotients for every reaction mixture. Selection of these 2 peaks is due to the facts that they do not interfere the spectra of the mixture while being the characteristic peak of the each component (Ochoa- 
Gómez et al., 2009). Then, reference graph as indicated in Fig. 1 was applied as the calibration curve generated from the mixtures (glycerol:glycerol carbonate) of different ratios (wt\%) such as $100 / 0$, $80 / 20,60 / 40,40 / 60,20 / 80$ and $0 / 100$ respectively.

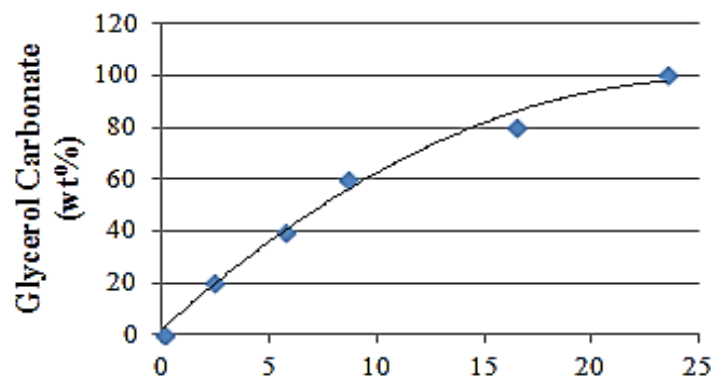

Ratio of 1775/920 $\mathrm{cm}^{-1}$ Peak Area

Fig. 1 FTIR calibration curve for glycerol carbonate determination in glycerol/glycerol carbonate mixtures.

The conversion $(\mathrm{C}, \%)$ and yield $(\mathrm{Y}, \%)$ were calculated from the Equation 1 and Equation 2 respectively:

$$
\begin{aligned}
& \mathbf{C}(\%)=\frac{100 \cdot \mathbf{M}_{0 G}-\mathbf{M} \cdot \mathbf{X}_{\mathrm{G}}}{\mathbf{M}_{0 \mathrm{G}}} \\
& \mathbf{Y}(\%)=\frac{\mathbf{M} \cdot \frac{\mathrm{X}_{\mathrm{GC}}}{\mathrm{MW}_{\mathrm{GC}}}}{\frac{\mathrm{M}_{0 \mathrm{G}}}{\mathrm{MW}_{\mathrm{G}}}} \mathbf{X 1 0 0} \%
\end{aligned}
$$

Where M_0G was the initial glycerol mass (g), $M$ was the total mass of the residue after evaporation of methanol and DMC (g), X_G and $\mathrm{X} \_\mathrm{GC}$ were the glycerol concentration $(\mathrm{wt} \%)$ and glycerol carbonate concentration (wt\%) in the residue, MW_G and MW_GC were the molecular weight of glycerol and glycerol carbonate respectively.

\section{Response surface methodology}

Response surface methodology (Lips-Wiersma et al., 2009) was applied with the experiments designed in accordance with the 3 different parameters which included the reaction temperature, reaction time and molar ratio of dimethyl carbonate (DMC) to pure glycerol as listed in Table 1. With the application of RSM, the effect of each different parameter on transesterification process could be analyzed while optimizing the reaction conditions for the reaction. Subsequently, the analysis of the experimental results were conducted by analysis of variance (ANOVA) at which performed by Design Expert Software (version 6.0.6, State-Ease, Inc., Minneapolis, MN).

Table 1 Designed experiments.

\begin{tabular}{cccc}
\hline Run & $\begin{array}{c}\text { Reaction } \\
\text { Temperature } \\
\left({ }^{\circ} \mathrm{C}\right)\end{array}$ & $\begin{array}{c}\text { Reaction Time } \\
\text { (hrs) }\end{array}$ & $\begin{array}{c}\text { Molar Ratio } \\
\text { (DMC: Gly) }\end{array}$ \\
\hline 1 & 70 & 1.50 & 3.00 \\
2 & 70 & 1.50 & 3.00 \\
3 & 70 & 1.50 & 5.00 \\
4 & 80 & 1.50 & 3.00 \\
5 & 60 & 1.50 & 3.00 \\
6 & 70 & 1.50 & 3.00 \\
7 & 60 & 0.50 & 1.00 \\
8 & 70 & 0.50 & 3.00 \\
9 & 70 & 2.50 & 3.00 \\
10 & 80 & 0.50 & 5.00 \\
11 & 70 & 1.50 & 3.00 \\
12 & 70 & 1.50 & 3.00 \\
13 & 80 & 2.50 & 1.00 \\
14 & 60 & 2.50 & 5.00 \\
15 & 70 & 1.50 & 1.00 \\
\hline
\end{tabular}

\section{RESULTS AND FINDINGS}

The calculated conversion and yield by FTIR method for glycerol transesterification were summarized in Table 2. The conversion obtained was ranged from $15.93 \%$ (Run 10) to $96.22 \%$ (Run 5). Meanwhile, the yield recorded was ranged from $11.06 \%$ (Run 8) to 95.83\% (Run 5). Referring to Table 1, higher reaction temperature (Run 10) reduced the conversion greatly. Nevertheless, lower reaction time (Run 8) reduced the yield vividly. In brief, $60{ }^{\circ} \mathrm{C}$ reaction temperature, moderate reaction time (1.5 hours) and 3.0 reactants molar ratio gave the highest conversion and yield.

Table 2 Glycerol conversion and yield for glycerol carbonate (GC) from glycerol (Gly) transesterification via FTIR Analysis.

\begin{tabular}{ccccccc}
\hline Run & $\begin{array}{c}\text { Initial } \\
\text { Mass (g) }\end{array}$ & $\begin{array}{c}\text { Residual } \\
\text { Mass }(\mathbf{g})\end{array}$ & $\begin{array}{c}\text { Gly } \\
(\mathbf{w t} \%)\end{array}$ & $\begin{array}{c}\text { GC } \\
(\mathbf{w t} \%)\end{array}$ & $\begin{array}{c}\text { Conversion } \\
(\%)\end{array}$ & $\begin{array}{c}\text { Yield } \\
(\%)\end{array}$ \\
\hline 1 & 9.2426 & 6.8432 & 24.9206 & 75.0794 & 81.55 & 43.35 \\
2 & 9.2113 & 8.5587 & 17.8091 & 82.1909 & 83.45 & 59.55 \\
3 & 9.2115 & 11.2240 & 16.2998 & 83.7002 & 80.14 & 79.53 \\
4 & 9.2231 & 8.1977 & 12.0044 & 87.9956 & 89.33 & 61.00 \\
5 & 9.2307 & 11.6942 & 3.0020 & 96.9980 & 96.22 & 95.83 \\
6 & 9.2493 & 7.6674 & 31.9210 & 68.0790 & 73.54 & 44.01 \\
7 & 9.2192 & 5.1251 & 37.0114 & 62.9986 & 60.21 & 27.31 \\
8 & 9.2110 & 5.2323 & 74.9980 & 25.0020 & 57.44 & 11.06 \\
9 & 9.2288 & 6.7500 & 78.9936 & 21.0064 & 42.22 & 11.98 \\
10 & 9.2485 & 10.7977 & 72.0070 & 27.9930 & 15.93 & 25.49 \\
11 & 9.2019 & 7.6464 & 16.2604 & 83.7396 & 86.49 & 54.26 \\
12 & 9.2507 & 7.8170 & 42.7057 & 57.2943 & 63.91 & 37.76 \\
13 & 9.2109 & 5.4295 & 64.5071 & 35.4929 & 61.98 & 16.32 \\
14 & 9.2745 & 11.0538 & 14.3639 & 85.6361 & 82.88 & 79.59 \\
15 & 9.2352 & 5.7549 & 71.4814 & 21.5186 & 55.46 & 13.86 \\
\hline
\end{tabular}

\section{Design of experiment (DOE)}

Design of Experiments (DOE) is the approach that used to investigate the effect of process parameters towards the responses chosen and thus facilitating the design optimization. The process parameters in this experiment were studied with the application of central composite design (CCD) of response surface methodology (RSM) approach. In this section, multiple regression method was used to analyze the experimental data in order to develop a mathematical model which can be used to predict the simulated result. Meanwhile, the responses chosen were glycerol conversion $(\%)$ and yield of glycerol carbonate $(\%)$. On the other hand, the parameters studied were reaction temperature $(\mathrm{A})$, reaction time $(\mathrm{B})$ and DMC:Gly molar ratio (C). The range of the process parameters studied was summarized in Table 3. For all the conducted experiments, the catalyst/glycerol molar ratio was set at 0.06 with the stirring speed fixed at $1000 \mathrm{rpm}$. All the equations generated by ANOVA were designated to calculate the glycerol conversion (\%) and glycerol carbonate yield $(\%)$ in the form of alpha factor instead of actual term as presented in Table 3 .

Table 3 Summary of process parameters and corresponding range.

\begin{tabular}{ccccccc}
\hline \multirow{2}{*}{ Parameters } & \multirow{2}{*}{ Name } & \multirow{2}{*}{ Unit } & \multicolumn{3}{c}{ Actual Factor } & \multicolumn{2}{c}{ Alpha Code } \\
\cline { 4 - 7 } & & & Low & High & Low & High \\
\hline $\mathrm{A}$ & Temperature & ${ }^{\circ} \mathrm{C}$ & 60 & 80 & -1 & 1 \\
$\mathrm{~B}$ & $\begin{array}{r}\text { Reaction Time } \\
\mathrm{hr}\end{array}$ & 0.5 & 2.5 & -1 & 1 \\
$\mathrm{C}$ & $\begin{array}{c}\text { DMC:Gly Molar } \\
\text { Ratio }\end{array}$ & - & 1 & 5 & -1 & 1 \\
\hline
\end{tabular}




\section{ANOVA for quadratic model of response 1 (conversion)}

Referring to Table 4 , the $\mathrm{F}$ value obtained was 9.45 which it implied that the quadratic model is significant as there was only $1.18 \%$ opportunity for the $\mathrm{F}$ value to happen due to the noise. Besides that, the p-value for Prob > F was 0.0118 which less than 0.05, indicating that the terms were significant in the model. Conversely, if the p-value for Prob > F was greater than 0.1, it implied that the terms of model were less likely to have significant effects towards the corresponding response. The high value of R-squared specified that about $98.29 \%$ of the data being fitted perfectly with model whereby it capable in explaining all the variability of the response. Generally, high value for both R-squared and adjusted R-squared were desirable to have well fitted model. Next, the adjusted R-squared value obtained was 0.9520 in which defined that $95.20 \%$ of the variation caused by independent variables were significantly affected the response variable. Meanwhile, the predicted R-squared value was 0.5813 indicating this quadratic model only possessed $58.13 \%$ predictive capability. However, the difference between the adjusted R-squared value and predicted $\mathrm{R}$-squared value was 0.3707 whereby theoretically it should not be more than 0.20 . The drastic difference might be because of the model included some insignificant predictors. In this model, terms for $\mathrm{AB}, \mathrm{AC}, \mathrm{A} 2$ and $\mathrm{B} 2$ had significant effect to the conversion response as the Prob $>\mathrm{F}$ values shown in Table 4 were $0.0239,0.0387,0.0219$ and 0.0038 respectively which less than 0.05 . The $\mathrm{F}$ value for lack of fit (LOF) was 0.13 and it considered as not significant relative to the pure error. Non-significant lack of fit was desirable as the model fitted the experimental data well. Moreover, the fitness of model can also be concluded based on the standard deviation from ANOVA as it having lower value than the mean which proved that possibility of significant mathematical model was induced. Next, the adequate precision that used to evaluate signal to noise ratio was 12.092 as listed in the Table 4 . The value obtained was desirable since it was larger than 4 which was the set point for adequate model discrimination and thus capable in navigating the design safe. The coefficient of variation (C.V.) for the quadratic model was $11.84 \%$ which implied that only minor of the input data deviated from the mean.

Table 4 ANOVA for response surface quadratic model of response 1 (conversion).

\begin{tabular}{|c|c|c|c|c|c|c|}
\hline Source & $\begin{array}{l}\text { Sum of } \\
\text { Square }\end{array}$ & DF & $\begin{array}{l}\text { Mean } \\
\text { Square }\end{array}$ & F-value & $\begin{array}{c}\text { P value } \\
\text { Prob }>\text { F }\end{array}$ & Significance \\
\hline Model & 5839.02 & 9 & 648.78 & 9.45 & 0.0118 & $\checkmark$ \\
\hline A & 23.60 & 1 & 23.60 & 0.35 & 0.5832 & $\mathrm{x}$ \\
\hline B & 115.82 & 1 & 115.82 & 1.69 & 0.2507 & $x$ \\
\hline C & 304.55 & 1 & 304.55 & 4.44 & 0.0891 & $x$ \\
\hline$A B$ & 704.72 & 1 & 704.72 & 10.26 & 0.0239 & $\checkmark$ \\
\hline$A C$ & 532.53 & 1 & 532.53 & 7.76 & 0.0387 & $\checkmark$ \\
\hline BC & 416.07 & 1 & 416.07 & 6.06 & 0.0571 & $\mathrm{X}$ \\
\hline$A^{2}$ & 740.36 & 1 & 740.36 & 10.78 & 0.0219 & $\checkmark$ \\
\hline$B^{2}$ & 1782.99 & 1 & 1782.99 & 25.97 & 0.0038 & $\checkmark$ \\
\hline$C^{2}$ & 173.29 & 1 & 173.29 & 2.52 & 0.1730 & $\mathrm{x}$ \\
\hline $\begin{array}{c}\text { Lack of } \\
\text { Fit }\end{array}$ & 10.75 & 1 & 10.75 & 0.13 & 0.7373 & $\mathrm{X}$ \\
\hline \multicolumn{2}{|c|}{ Std. Dev } & \multicolumn{2}{|c|}{8.92} & \multicolumn{2}{|c|}{ R-Squared } & 0.9445 \\
\hline \multirow{2}{*}{\multicolumn{2}{|c|}{$\begin{array}{l}\text { Mean } \\
\text { PRESS }\end{array}$}} & \multirow{2}{*}{\multicolumn{2}{|c|}{$\begin{array}{c}70.00 \\
2863.93\end{array}$}} & \multicolumn{2}{|c|}{ Adj R-Squared } & 0.8445 \\
\hline & & & & \multicolumn{2}{|c|}{ red R-Squared } & 0.5368 \\
\hline \multicolumn{2}{|c|}{ Variation (C.V.) } & \multicolumn{2}{|c|}{$11.84 \%$} & \multicolumn{2}{|c|}{ Adeq Precision } & 12.092 \\
\hline
\end{tabular}

Referring to Table 4, a linear regression equation was deduced by which insignificant terms were eliminated while significant terms were included in the equation. The equation generated was indicated as Equation 3 below:

Conversion $(\%)=76.97+22.99 A B-19.98 A C+16.82 A^{2}-26.11 B^{2}$

Based on the Equation 3, the term $\mathrm{AB}$ in which the actual term was (temperature*reaction time) having positive effect towards the conversion response. On the other hand, AC term or (temperature*DMC:Gly molar ratio) specified negative interaction towards the conversion. Subsequently, the A2 term demonstrated positive interaction to the conversion while B2 term indicating negative effect toward the Equation 3.

\section{Parameters affecting conversion}

Theoretically, conversion of glycerol is favorable in the condition of increasing reaction temperature as the glycerol carbonate generation with pure glycerol is thermodynamically related to the chemical equilibrium constant (Li \& Wang, 2011). This is because of more molecules gain the minimum energy required for the effective collision when the reaction temperature is enhanced that eventually leading to the increment of the reaction rate (Kotz et al., 2008). Li and Wang (2011) reported that with the reaction temperature increases within the range from $40{ }^{\circ} \mathrm{C}$ to $80{ }^{\circ} \mathrm{C}$ would promote the reaction rate by enhancing the chemical equilibrium constant. However, as referring to Fig. 2, there was a deviation at which the conversion was dropped when the reaction temperature set at $70{ }^{\circ} \mathrm{C}$. This deviation might because of the extremely robust reaction at $60{ }^{\circ} \mathrm{C}$ which leading to the upsurge of conversion initially and caused turbulent or instable reaction that eventually decrease conversion when the reaction temperature proceed to $70{ }^{\circ} \mathrm{C}$. After the reaction regaining stability, the glycerol conversion increased gradually with the further increasing of reaction temperature as evidenced by Fig. 2. Nevertheless, A2 or (reaction temperature) 2 term was classified as one of critical term that having positive effect towards the percentage of conversion as indicated in Equation 3. In other words, with the increased of operating temperature, the conversion of glycerol will be enhanced as according to the Equation 3. With further increment of reaction temperature to $100{ }^{\circ} \mathrm{C}$ or beyond optimum temperature, the conversion normally experiences reduction of conversion due to the vaporization of volatile dimethyl carbonate (DMC) reactant which its' boiling point at $90{ }^{\circ} \mathrm{C}$.

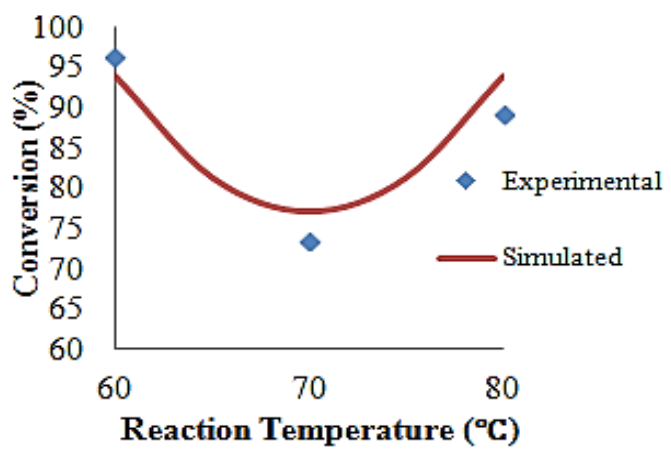

Fig.2 One factor plot for effect of parameter a (reaction temperature) on conversion with other parameters set at centre point for the selected range.

According to Fig. 3, the initial conversion of glycerol was low but increased gradually with the increasing of the reaction time. This was due to a longer time was needed at the beginning for the active $\mathrm{Ca}$ species to form so that the reaction could take place (Simanjuntak et al., 2011). There was a reduction of conversion when the reaction time was beyond 1.5 hours. According to Ochoa-Gómez (2009), about $91.1 \%$ of conversion can be achieved with the reaction time of 0.5 hour. Therefore, the 1.5 hours was sufficient for the reaction to achieve high glycerol conversion. The conversion dropped vividly once the reaction time was beyond 1.5 hours as evidenced from Fig. 3 . In addition, with the prolonged of reaction time, decomposition of glycerol carbonate to glycerol might take place that causes the poor conversion of glycerol (Tudorache et al., 2014). A shorter reaction time is desirable to optimize the operating cost yet to reduce the possibility of undesired reaction or secondary reaction to be occurred (Teng et al., 2014). Based on Equation 3, B2 or (reaction time) 2 term was one of the crucial term by which showing negative effect towards the conversion response. 
Besides that, the synergic effect of $\mathrm{AB}$ (temperature*reaction time) term was significant in which demonstrating positive effect towards the conversion response. By increasing the reaction time and reaction temperature gradually, more molecules gained adequate energy for effective collision at the same time having sufficient time for promoting the interaction between catalyst and reactants to form active $\mathrm{Ca}$ species and thus enhanced the glycerol conversion. The interaction between synergic effects of $\mathrm{AB}$ term on conversion was illustrated in Fig. 4.

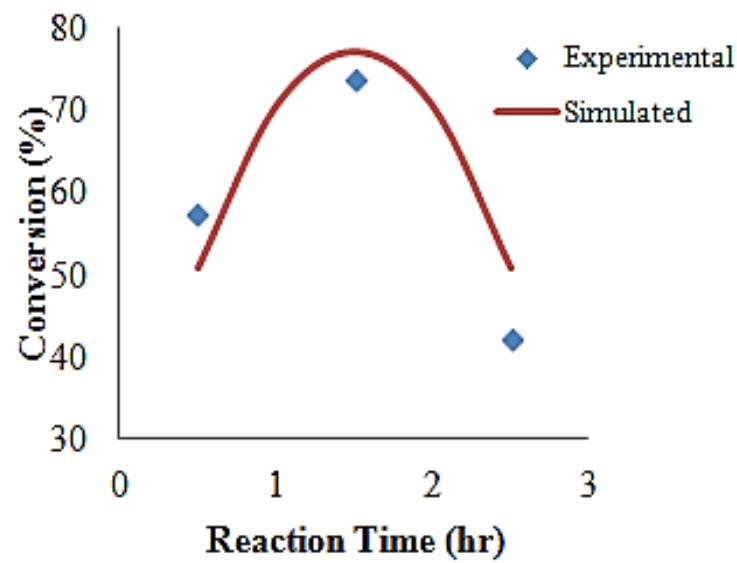

Fig 3 One factor plot for effect of parameter B (reaction time) on conversion with other parameters set at centre point for the selected range.

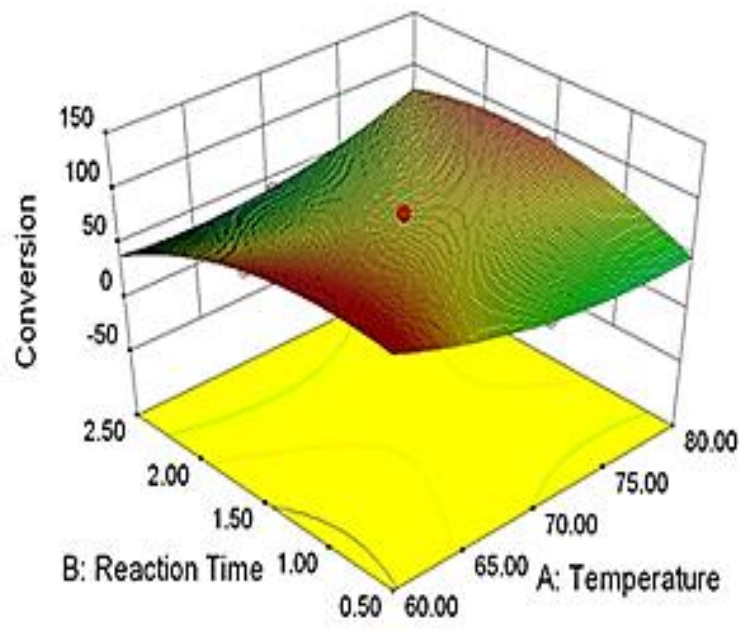

Fig 4 Response surfaces of $A B$ term for conversion model during pure glycerol reaction.

According to the experimental result, the conversion of glycerol increased gradually with the increasing of DMC:Gly molar ratio. Higher ratio of carbonate source such as dimethyl carbonate could shift the chemical equilibrium towards glycerol carbonate formation which in turn enhancing glycerol conversion (Li \& Wang, 2011). Nevertheless, the simulated result indicated that conversion remained constant regardless of the gradually increased amount of dimethyl carbonate as presented in Fig. 5. This was because the absence of $\mathrm{C}$ term or DMC:Gly molar ratio as significant term in the Equation 3 which was due to p-value Prob > F more than significant level. This might because of the role of DMC:Gly molar ratio is less apparent in the conversion of glycerol but somehow having prominent effect in the yield of glycerol carbonate.

Instead of just solely $\mathrm{C}$ term, the synergic effect of $\mathrm{AC}$ (reaction temperature*DMC:Gly molar ratio) showed greater effect towards the conversion. According to Equation 3, AC term indicated negative effect towards the conversion response which means whenever the value for $\mathrm{AC}$ term increases, it would reduce the glycerol conversion. With combined parameters of reaction temperature and DMC:Gly molar ratio increased at the same time, the dimethyl carbonate (DMC) would experience fast evaporation due to its' heat sensitive and highly volatile characteristic. Therefore, before gaining the sufficient amount of energy for effective collision, the dimethyl carbonate would change into gas phase and made it difficult for the reaction to take place that eventually leading to the reduction of glycerol conversion. The interaction between $\mathrm{AC}$ term and conversion response was illustrated in Fig. 6.

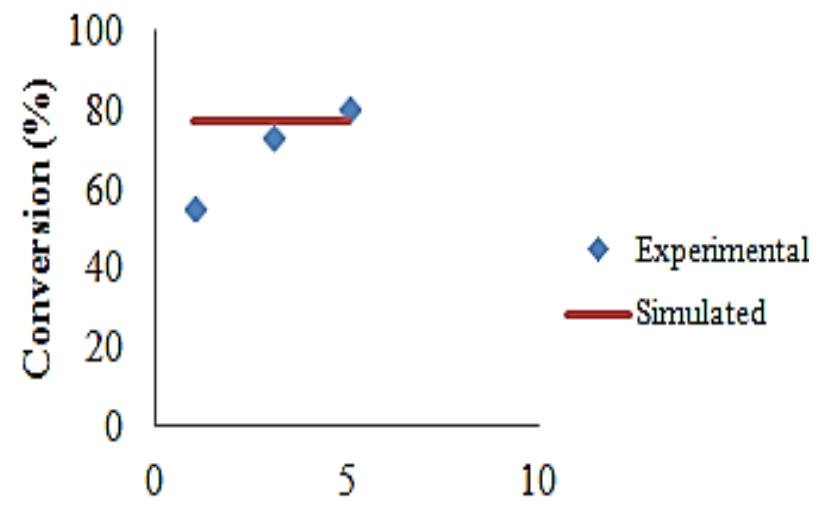

\section{DMC:Gly Molar Ratio}

Fig.5 One factor plot for effect of parameter C (DMC:Gly Molar Ratio) on conversion with other parameters set at centre point for the selected range.

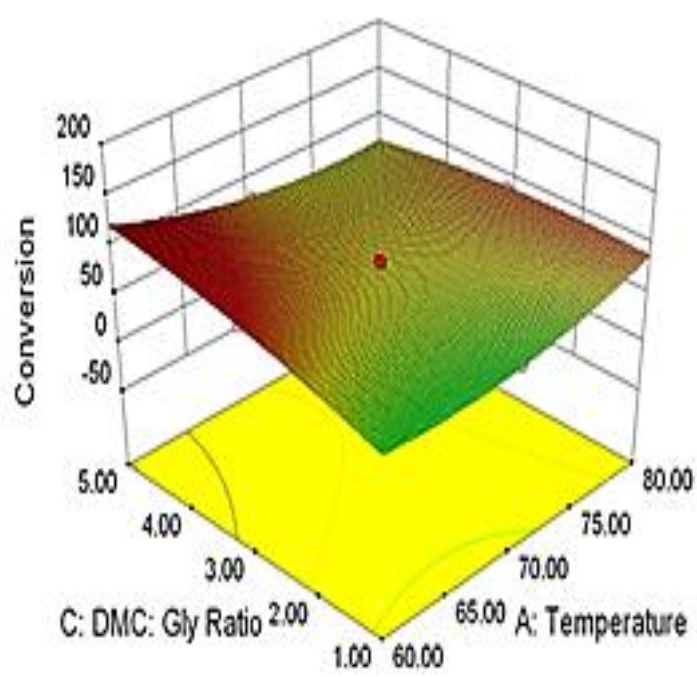

Fig.6 Response surfaces of AC term for conversion model for reaction.

\section{ANOVA for Quadratic Model of Response 2 (Yield)}

Referring to Table 5, the suggested response surface quadratic model was significant as the F-value obtained was 17.28 where there was only $0.29 \%$ opportunity that the model could be inaccurate due to noise. The coefficient of determination (R2) was prominent whereby $96.89 \%$ of variability of response data was being explained. In other words, this model fitted the data nicely. Subsequently, the accuracy of the suggested model was further determined by assessing the adjusted R-squared value which was 0.9128 . In other words, $91.28 \%$ of variation caused by the independent variables were strongly influencing this response variable. The predicted R-squared value obtained was 0.8300 considered acceptable as the difference between adjusted R-squared and predicted R-squared values were less than 0.20 and thus it shown that the quadratic model possessed $83 \%$ of predictive ability. 
A linear regression equation was deduced according to Table 5, whereby insignificant terms were eliminated while significant terms were included in the equation. The equation generated was presented as Equation 4 below:

Yield $(\%)=48.39-17.42 A+32.84 C+29.26 A^{2}-37.64 B^{2}$

Based on Equation 4, term $A$ in which the actual term was reaction temperature having negative effect towards the yield response. On the other hand, $\mathrm{C}$ term which was the DMC: Gly molar ratio showing positive effect towards the percentage of yield. Next, A2 term or (temperature) 2 demonstrated positive interaction with the equation while B2 term or (reaction time) 2 indicated negative effect towards the yield.

Table 5 ANOVA for response surface quadratic model of response 2 (yield).

\begin{tabular}{|c|c|c|c|c|c|c|}
\hline Source & $\begin{array}{l}\text { Sum of } \\
\text { Square }\end{array}$ & DF & $\begin{array}{l}\text { Mean } \\
\text { Square }\end{array}$ & F-value & $\begin{array}{c}\mathbf{P} \\
\text { value } \\
\text { Prob } \\
>\mathbf{F}\end{array}$ & Sig \\
\hline Model & 9976.19 & 9 & 1108.47 & 17.28 & 0.0029 & $\sqrt{ }$ \\
\hline A & 606.56 & 1 & 606.56 & 9.46 & 0.0276 & $\checkmark$ \\
\hline B & 0.42 & 1 & 0.42 & $\begin{array}{l}\text { 6.599E- } \\
003\end{array}$ & 0.9384 & $x$ \\
\hline$C$ & 2156.27 & 1 & 2156.27 & 33.62 & 0.0022 & $\checkmark$ \\
\hline$A B$ & 407.05 & 1 & 407.05 & 6.35 & 0.0532 & $x$ \\
\hline$A C$ & 141.93 & 1 & 141.93 & 2.21 & 0.1970 & $X$ \\
\hline $\mathrm{BC}$ & 1.74 & 1 & 1.74 & 0.027 & 0.8756 & $X$ \\
\hline$A^{2}$ & 2239.07 & 1 & 2239.07 & 34.91 & 0.0020 & $\checkmark$ \\
\hline$B^{2}$ & 3704.53 & 1 & 3704.53 & 57.76 & 0.0006 & $\checkmark$ \\
\hline$C^{2}$ & 15.83 & 1 & 15.83 & 0.25 & 0.6403 & $x$ \\
\hline $\begin{array}{l}\text { Lack of } \\
\text { Fit }\end{array}$ & 5.91 & 1 & 5.91 & 0.075 & 0.7977 & $x$ \\
\hline \multicolumn{2}{|l|}{ Std. Dev } & \multicolumn{2}{|l|}{8.01} & \multicolumn{2}{|l|}{ R-Squared } & 0.9689 \\
\hline \multicolumn{2}{|l|}{ Mean } & \multicolumn{2}{|l|}{44.06} & \multicolumn{2}{|l|}{ Adj R-Squared } & 0.9128 \\
\hline \multicolumn{2}{|c|}{ PRESS } & \multicolumn{2}{|c|}{1750.50} & \multicolumn{2}{|l|}{$\begin{array}{l}\text { Pred R- } \\
\text { Squared }\end{array}$} & 0.8300 \\
\hline \multicolumn{2}{|c|}{$\begin{array}{c}\text { Coefficient of } \\
\text { Variation (C.V.) }\end{array}$} & \multicolumn{2}{|l|}{$18.18 \%$} & \multicolumn{2}{|l|}{ Adeq Precision } & 12.964 \\
\hline
\end{tabular}

\section{Parameters affecting yield}

According to Equation 4, A (reaction temperature) term affected the yield of glycerol carbonate negatively while the A2 (reaction temperature) 2 gave positive influence towards the yield of glycerol carbonate. Based on Fig. 7, high yield of glycerol carbonate was achieved at reaction temperature $60{ }^{\circ} \mathrm{C}$. Subsequently, the yield of glycerol carbonate experienced great reduction at reaction temperature beyond $60{ }^{\circ} \mathrm{C}$ nonetheless glycerol carbonate yield increased gradually with the reaction temperature increased from $70{ }^{\circ} \mathrm{C}$ to 80 ${ }^{\circ} \mathrm{C}$. Theoretically, the chemical reaction rate increases with the reaction temperature range from $40^{\circ} \mathrm{C}$ to $80^{\circ} \mathrm{C}$ which in turn enhancing the yield of glycerol carbonate ( $\mathrm{Li} \&$ Wang, 2011). As mentioned earlier, the poor glycerol conversion at $70{ }^{\circ} \mathrm{C}$ obtained previously eventually leading to lower of glycerol carbonate yield. The deviation of the glycerol carbonate yield obtained might because of the reaction temperature at which catalyst added into the mixture of reactants was actually higher than $60{ }^{\circ} \mathrm{C}$. When the catalyst was first added, extremely vigorous reaction took place at which the amount of dimethyl carbonate available was reduced by great heat generated. After the vigorous reaction caused by high reaction temperature, the turbulence of the reaction was reduced and became stable and thus the yield of glycerol carbonate increased gradually with the increment of reaction temperature.

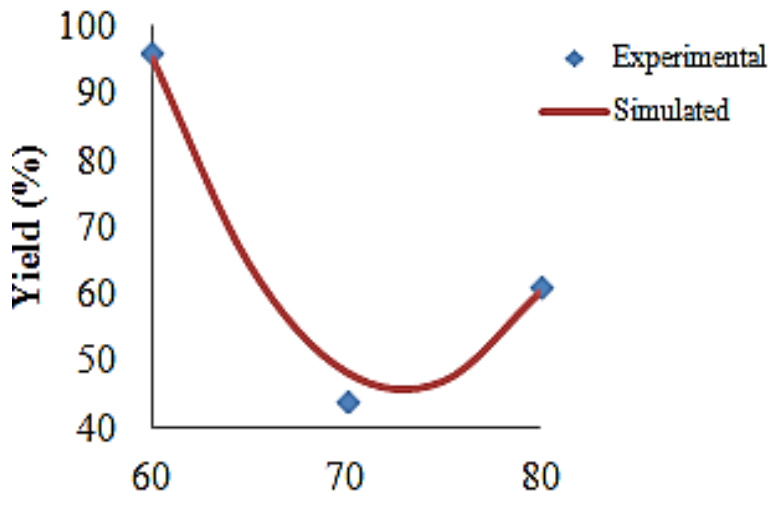

Reaction Temperature $\left({ }^{\circ} \mathrm{C}\right)$

Fig.7 One factor plot for effect of parameter A (reaction temperature) on yield with other parameters set at centre point of the selected range.

Referring to Equation 4, B (reaction time) was not included meanwhile B2 (reaction time)2 was included but it affected the yield negatively. Fig. 8 indicated that the yield of glycerol carbonate increased with gradual increment of reaction time from 0.5 hour to 1.5 hours. This was because induction period was needed for the soluble active $\mathrm{Ca}$ species to be formed by the interaction between the glycerol and calcium oxide catalyst that eventually promoting the glycerol carbonate formation (Simanjuntak et al., 2011). Moreover, high yield of glycerol carbonate could be achieved in 0.5 hour (Ochoa-Gómez et al., 2009). Therefore, the reaction time range from 0.5 hour to 1.5 hours was sufficient to produce high yield of glycerol carbonate. Nevertheless, the yield of glycerol carbonate experienced reduction when the reaction time was beyond 1.5 hours. This might be because of undesired secondary reaction took place where the decomposition or decarboxylation of glycerol carbonate to glycidol occurred. Prolonged reaction time does not increase the yield of glycerol carbonate due to the longer time for the interaction between the glycerol carbonate with methanol by-product to be occurred and thus decomposition took place (Climent et al., 2010). With reaction time more than 48 hours, by-product glycerol dicarbonate would form instead of glycerol carbonate (Rokicki et al., 2005). In brief, the optimum reaction time for attaining highest possible yield of glycerol carbonate was 1.5 hours as according to the Fig. 8 .

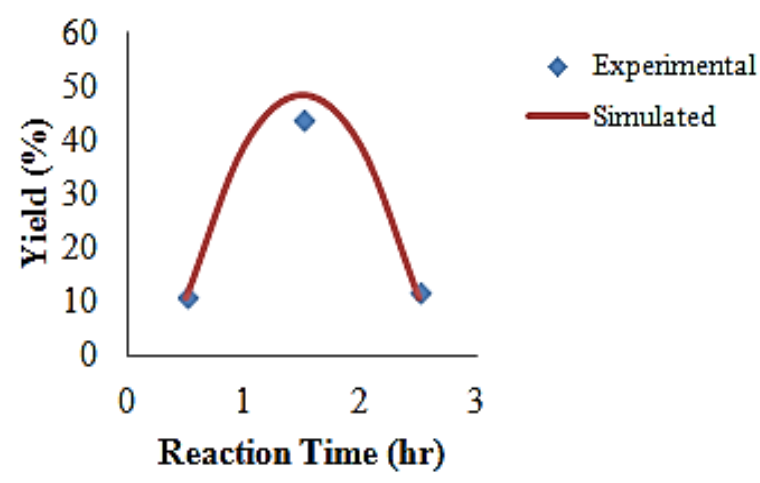

Fig.8 One factor plot for effect of parameter B (reaction time) on yield with other parameters set at centre point of the selected range.

Referring to Equation 4, C (DMC:Gly molar ratio) was one of the crucial parameter that strongly affected the yield of glycerol carbonate positively. According to Fig. 9, the yield of glycerol carbonate increased proportionally with increasing DMC:Gly molar ratio that ranged from 1 to 5 . As mentioned earlier, production of glycerol carbonate was a reversible reaction whereby excess dimethyl carbonate was essential to shift the reaction to the formation of glycerol carbonate and thus causing the positive effect on yield (Chiappe \& Rajamani, 2011) as illustrated in Fig. 9. In addition, when excess dimethyl carbonate was involved in the reaction, it could solve 
the immiscibility between hydrophilic glycerol and hydrophobic dimethyl carbonate that eventually eliminated the mass transfer limitation between the reactants (Pan et al., 2012). Consequently, it could promote the yield of glycerol carbonate. The yield of glycerol carbonate escalating gradually with the DMC:Gly molar ratio increases from 1 to 5 (Malyaadri et al., 2011). Based on Fig. 9, the experimental result was agreed with simulated result whereby the yield of glycerol carbonate increased with the increment of DMC:Gly molar ratio. Nevertheless, excessive amount of dimethyl carbonate could have adverse effect towards the yield of glycerol carbonate. Beyond the optimum DMC:Gly molar ratio, it would hinder the formation of soluble active $\mathrm{Ca}$ species by limiting the interaction between the glycerol and calcium oxide catalyst which in turn lowering the yield of glycerol carbonate (Simanjuntak et al., 2011). Moreover, the excessive of dimethyl carbonate (10 fold) could cause the great formation of co-product known as glycerol dicarbonate that appeared in yellowish white crystal (Rokicki et al., 2005). However, this was less likely to happen as the glycerol carbonate produced was stable as there was no foreign impurities interference and thus not susceptible to secondary reaction unless 10 fold of DMC was used.

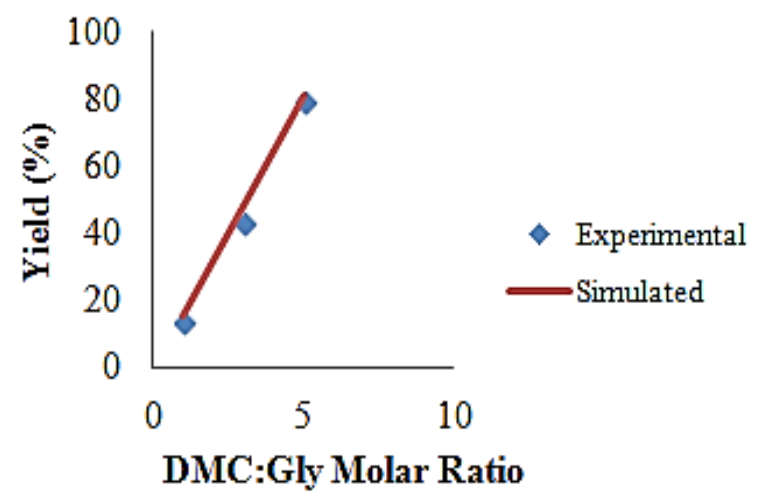

Fig.9 One factor plot for effect of parameter C (DMC:Gly molar ratio) on yield with other parameters set at centre point of the selected Range.

\section{Optimization}

According to Table 6, Solution 1 was chosen due to the several criterias stated below. Firstly, the reaction time was moderate among these 5 solutions which satisfied the criteria of industrial feasibility. The reaction time have to be as low as possible to optimize capital investment yet with desirable yield of glycerol carbonate. Solution 5 was disqualified due to harsher reaction conditions yet with undesired glycerol conversion and glycerol carbonate yield obtained which were only $85.60 \%$ and $78.80 \%$ respectively. In short, it was not a cost effective reaction. Next, Solution 4 was disqualified too, even with milder reaction conditions because of the unsatisfying glycerol conversion and glycerol carbonate yield which were only $97.36 \%$ and $80.70 \%$ respectively. In addition, Solution 3 was not chosen even the yield of glycerol carbonate was higher than yield from Solution 1 by $3.21 \%$. This was because of the reaction time and DMC:Gly molar ratio needed were higher which were 1.41 hours and 3.93 DMC:Gly molar ratio respectively as compared to 1.19 hours and 3.04 DMC:Gly molar ratio from Solution 1. Higher investment capital and operating cost were needed to compensate for the high conversion and yield achieved and thus it was not cost effective. Subsequently, the DMC:Gly molar ratio in Solution 2 needed for achieving 100\% of glycerol carbonate yield was 1.6 times higher than DMC:Gly molar ratio from Solution 1 and with slightly higher reaction temperature. Undoubtedly, higher cost is needed for the process followed the reaction conditions from Solution 2. In brief, Solution 1 was chosen to optimize pure glycerol transesterification with milder reaction conditions yet with higher glycerol conversion and yield of glycerol carbonate obtained.
Table 6 Optimization of transesterification.

\begin{tabular}{|c|c|c|c|c|c|c|}
\hline$\frac{5}{\frac{5}{3}}$ & 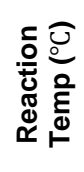 & 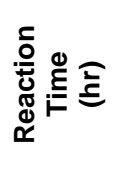 & 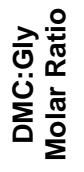 & $\begin{array}{l}\frac{5}{0} \\
\stackrel{0}{\frac{0}{2}} \\
\stackrel{0}{0}\end{array}$ & 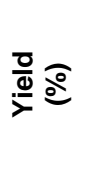 & \\
\hline 1 & 60.16 & 1.19 & 3.04 & 100.00 & $\underline{96.36}$ & Suggested \\
\hline 2 & 64.27 & $\overline{1.11}$ & $\overline{4.92}$ & $\overline{97.27}$ & $\overline{100.00}$ & \\
\hline 3 & 62.15 & 1.41 & 3.93 & 100.00 & 99.57 & \\
\hline 4 & 60.00 & 1.03 & 2.37 & 97.36 & 80.70 & \\
\hline 5 & 80.00 & 1.88 & 4.72 & 85.60 & 78.80 & \\
\hline
\end{tabular}

\section{Compare and contrast}

With the reaction conditions at $60{ }^{\circ} \mathrm{C}$ reaction temperature, at 1.5 hours reaction time and 3:1 of DMC:Gly molar ratio resulted the highest glycerol conversion and glycerol carbonate yield which were $96.22 \%$ and $95.83 \%$ respectively in this research. Mathematical models generated that used to predict the glycerol conversion and glycerol carbonate yield as the function of 3 variables studied and their interactions had been obtained. It was observed that the synergic effects of combined parameters seem to have prominent influence on the glycerol conversion instead of single parameter as indicated in Equation 3. On the contrary, reaction temperature was observed to be negatively affecting the glycerol carbonate yield while DMC:Gly molar ratio gave positive result on the glycerol carbonate yield as shown in Equation 4.

Referring to the study related to $\mathrm{CaO}$ catalyzed glycerol carbonate, yield reported were more than $90 \%$ with the reaction temperature fixed at $75{ }^{\circ} \mathrm{C}$, the reaction time was ranged from 0.5 hour to 1.5 hour and the reactant was excess in DMC (DMC:Gly (2:1 - 5.1) molar ratio) (Climent et al., 2010; Ochoa-Gómez et al., 2009; Simanjuntak et al., 2011). The highest yield was $94 \%$ with lower DMC molar ratio $(2: 1)$ and with a shorter reaction time at 0.5 hour (Simanjuntak et al., 2011). With reaction temperature reduced to $60.16{ }^{\circ} \mathrm{C}$, longer reaction time (1.19 hour) and increased molar ratio of DMC:Gly (3.04), higher yield (96.36\%) and complete conversion could be achieved. Compared to the conversion and yield results summarized in Table 2, with slightly shorten the reaction time shown in Table 1, the glycerol conversion would increase to $100 \%$.

\section{CONCLUSION}

As a conclusion, the obtainable highest glycerol conversion and glycerol carbonate yield were $96.22 \%$ and $95.83 \%$ respectively at 60 ${ }^{\circ} \mathrm{C}$ reaction temperature with 1.5 hours reaction time accompanied with the utilization of DMC:Gly molar ratio at 3. Reaction time influenced the least to production yield compared to reaction temperature and molar ratio for reactants. On the other hand, all the parameters studied seem to have equal significance to the conversion of glycerol in this study. After optimization, $100 \%$ of glycerol conversion and $96.36 \%$ of glycerol carbonate yield could be achieved at the reaction temperature of $60.16{ }^{\circ} \mathrm{C}$ at 1.19 hours reaction time with DMC:Gly molar ratio at 3.04. In brief, with moderate reaction temperature fixed at $60{ }^{\circ} \mathrm{C}$, complete conversion is possible and yield could be increased to more than $95 \%$.

\section{REFERENCES}

Buasri, A., Chaiyut, N., Loryuenyong, V., Worawanitchaphong, P., Trongyong, S. 2013. Calcium oxide derived from waste shells of mussel, cockle, and scallop as the heterogeneous catalyst for biodiesel production. The Scientific World Journal, 2013, 1-7.

Chiappe, C., Rajamani, S. 2011. Synthesis of glycerol carbonate from glycerol and dimethyl carbonate in basic ionic liquids. Pure and Applied Chemistry, 84(3), 755-762.

Climent, M. J., Corma, A., De Frutos, P., Iborra, S., Noy, M., Velty, A., Concepción, P. 2010. Chemicals from biomass: Synthesis of glycerol carbonate by transesterification and carbonylation with urea with 
hydrotalcite catalysts. The role of acid-base pairs. Journal of Catalysis, 269(1), 140-149.

Coldea, T. E., Socaciu, C., Fetea, F., Ranga, F. A., Pop, R. M., Florea, M 2013. Rapid quantitative analysis of ethanol and prediction of methanol content in traditional fruit brandies from romania, using FTIR spectroscopy and chemometrics. Notulae Botanicae Horti Agrobotanici Cluj-Napoca, 41(1), 143-149.

Farndon, J. 2000. Calcium (1st ed.). New York: Benchmark Books.

Gupta, C. K. 2006. Chemical metallurgy: Principles and practice. Weinheim: John Wiley \& Sons.

Herbert, J. M. 1985. Ceramic dielectrics and capacitors (Vol. 6). Switzerland: Gordon and Breach Science Publishers.

Indran, V. P., Zuhaimi, N. A. S., Deraman, M. A., Maniam, G. P., Yusoff, M. M., Hin, T. Y. Y., Rahim, M. H. A. 2014. An accelerated route of glycerol carbonate formation from glycerol using waste boiler ash as catalyst. RSC Advances, 4(48), 25257-25257.

Kogel, J. E., Trivedi, N. C., Barker, J. M., Krukowski, S. T. 2006. Industrial minerals \& rocks: Commodities, markets, and uses (7th ed.). Colorado: Society for Mining, Metallurgy, and Exploration.

Kotz, J., Treichel, P., Townsend, J. 2008. Chemistry and chemical reactivity (7th ed.). Canada: Cengage Learning.

Kowalski, S. J. 2012. Thermomechanics of drying processes (1st ed.). New York: Springer Berlin Heidelberg.

Lanjekar, K., Rathod, V. K. 2013. Utilization of glycerol for the production of glycerol carbonate through greener route. Journal of Environmental Chemical Engineering, 1(4), 1231-1236.

Lesbani, A., Ceria Sitompul, S. O., Mohadi, R., Hidayati, N. 2016 Characterization and utilization of calcium oxide (cao) thermally decomposed from fish bones as a catalyst in the production of biodiesel from waste cooking oil. Makara Journal of Technology, 20(3), 121-121.

Letcher, T. M., Scott, J. L. 2012. Materials for a sustainable future. United Kingdom: Royal Society of Chemistry.

Li, J., Wang, T. 2011. Chemical equilibrium of glycerol carbonate synthesis from glycerol. Journal of Chemical Thermodynamics, 43(5), 731-736.

Lips-Wiersma, M., Dean, K. L., Fornaciari, C. J. 2009. Theorizing the dark side of the workplace spirituality movement. Journal of management inquiry, 18(4), 288-300

Malyaadri, M., Jagadeeswaraiah, K., Sai Prasad, P. S., Lingaiah, N. 2011. Synthesis of glycerol carbonate by transesterification of glycerol with dimethyl carbonate over $\mathrm{Mg} / \mathrm{Al} / \mathrm{Zr}$ catalysts. Applied Catalysis A. General, 401(1), 153-157.

Mathers, R. T., Meier, M. A. R. 2011. Green polymerization methods: Renewable starting materials, catalysis and waste reduction. Weinheim: Wiley.
Mohadi, R., Anggraini, K., Riyanti, F., Lesbani, A. 2016. Preparation calcium oxide $(\mathrm{CaO})$ from chicken eggshells. Sriwijaya Journal of Environment, $1(2), 32-35$.

Ochoa-Gómez, J. R., Gómez-Jiménez-Aberasturi, O., Maestro-Madurga, B., Pesquera-Rodríguez, A., Ramírez-López, C., Lorenzo-Ibarreta, L., Torrecilla-Soria, J., Villarán-Velasco, M. C. 2009. Synthesis of glycerol carbonate from glycerol and dimethyl carbonate by transesterification: Catalyst screening and reaction optimization. Applied Catalysis A: General, 366(2), 315-324.

Pan, S., Zheng, L., Nie, R., Xia, S., Chen, P., Hou, Z. 2012. Transesterification of glycerol with dimethyl carbonate to glycerol carbonate over $\mathrm{Na}$-based zeolites. Chinese Journal of Catalysis, 33(11-12), 1772-1777.

Rokicki, G., Rakoczy, P., Parzuchowski, P., Sobiecki, M. 2005. Hyperbranched aliphatic polyethers obtained from environmentally benign monomer: Glycerol carbonate. Green Chemistry, 7(7), 529-529.

Simanjuntak, F. S. H., Kim, T. K., Lee, S. D., Ahn, B. S., Kim, H. S., Lee, H. 2011. CaO-catalyzed synthesis of glycerol carbonate from glycerol and dimethyl carbonate: Isolation and characterization of an active $\mathrm{Ca}$ species. Applied Catalysis A: General, 401(1-2), 220-225.

Sonnati, M. O., Amigoni, S., Taffin de Givenchy, E. P., Darmanin, T., Choulet, O., Guittard, F. 2013. Glycerol carbonate as a versatile building block for tomorrow: Synthesis, reactivity, properties and applications. Green Chemistry, 15(2), 283-306.

Stanmore, B. R., Gilot, P. 2005. Review - Calcination and carbonation of limestone during thermal cycling for $\mathrm{CO}_{2}$ sequestration. Fuel Processing Technology, 86(16), 1707-1743.

Tangboriboon, N., Kunanuruksapong, R., Sirivat, A. 2012. Preparation and properties of calcium oxide from eggshells via calcination. Materials Science-Poland, 30(4), 313-322.

Teng, W. K., Ngoh, G. C., Yusoff, R., Aroua, M. K. 2014. A review on the performance of glycerol carbonate production via catalytic transesterification: Effects of influencing parameters. Energy Conversion and Management, 88, 484-497.

Tudorache, M., Negoi, A., Tudora, B., Parvulescu, V. I. 2014. Environmentalfriendly strategy for biocatalytic conversion of waste glycerol to glycerol carbonate. Applied Catalysis B: Environmental, 146, 274-278.

Verma, C. L. 1993. Vertical-shaft limekiln technology. Nairobi: United Nations Centre for Human Settlments (Habitat).

Zabeti, M., Wan Daud, W. M. A., Aroua, M. K. 2009. Activity of solid catalysts for biodiesel production: A review. Fuel Processing Technology, 90(6), 770-777.

Zhang, Z., Rackemann, D. W., Doherty, W. O. S., O’Hara, I. M. 2013. Glycerol carbonate as green solvent for pretreatment of sugarcane bagasse. Biotechnology for Biofuels, 6(1), 153-153. 